\section{Commentary: A stitch too far}

\author{
Edward Y. Sako, MD, PhD
}

The complication of circumflex artery injury leading to regional ischemia during or related to mitral valve surgery has been well described. ${ }^{1}$ In their study, Caruso and colleagues $^{2}$ seek to better quantify the risk factors for this complication. They describe a case series of 95 consecutive patients who, in addition to the usual preoperative workup, underwent coronary computed tomography angiography (CCTA). The images were rigorously analyzed to determine the course of the circumflex artery relative to the mitral annulus. The region was divided into zones, and the distances from the artery to the annulus were reported.

The authors identify $3 \mathrm{~mm}$ as the critical distance, although admitting that they chose this value somewhat arbitrarily. Given this parameter, they also note that the most dangerous area is zone 1, the proximal circumflex/ posterolateral portion of the annulus. They found a $25 \%$ incidence of this critical value.

They go on to describe the steps that they take to minimize the risk of arterial injury in the presence of the critical distance. These include a median sternotomy approach, the use of flexible rings or bands for the annuloplasty, modifications to the ring or band, and avoiding suture placement in those regions.

The incidence of this complication in most series has been reported as $<2 \%{ }^{3,4}$ In addition, knowledge of the potential for this complication, prompt recognition when it occurs, and published responses have helped keep the rate of long-term consequences even lower. ${ }^{5}$ Nonetheless, prevention is the ultimate goal. This and other studies have shown that, unfortunately, preoperative coronary angiography is

From the Department of Cardiothoracic Surgery, University of Texas Health Science Center at San Antonio, San Antonio, Tex.

Disclosure: The author reported a financial relationship with Medtronic.

The Journal policy requires editors and reviewers to disclose conflicts of interest and to decline handling or reviewing manuscripts for which they may have a conflict of interest. The editors and reviewers of this article have no conflicts of interest.

Received for publication Oct 8, 2020; revisions received Oct 8, 2020; accepted for publication Oct 20, 2020; available ahead of print Oct 27, 2020.

Address for reprints: Edward Y. Sako, MD, PhD, Department of Cardiothoracic Surgery, University of Texas Health Science Center at San Antonio, Mail Code 7841, 7703 Floyd Curl Drive, San Antonio, TX 78229-3900 (E-mail: sako@uthscsa.edu). JTCVS Techniques 2020;4:130-1

2666-2507

Copyright $@ 2020$ The Authors. Published by Elsevier Inc. on behalf of The American Association for Thoracic Surgery. This is an open access article under the CC BY-NCND license (http://creativecommons.org/licenses/by-nc-nd/4.0/).

https://doi.org/10.1016/j.xjtc.2020.10.018

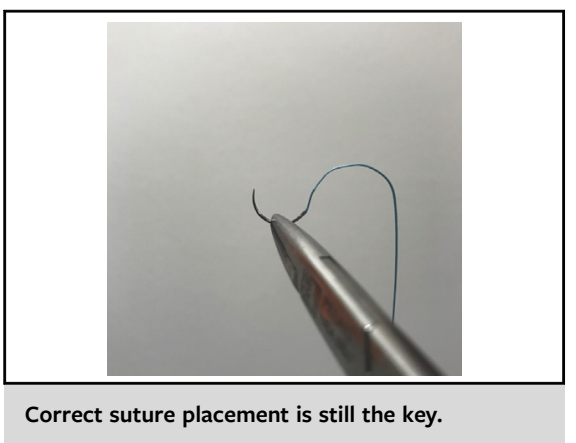

CENTRAL MESSAGE

Better knowledge of coronary anatomy may reduce the risk of circumflex artery injury during mitral valve surgery.

not sufficiently predictive of arterial injury. In addition, coronary angiography is not necessarily the standard of care in younger patients.

The maneuvers to avoid the complication that the authors describe should be viewed critically, as they may have a negative effect on the outcomes of these operations. Although the authors claim no changes in the results up to 1 year, they do not address the long-term consequences of modifying annuloplasty devices and skipping areas of suture fixation.

As is often the case, more study is warranted. This would include collecting evidence to show that the proximity of the artery is indeed a major risk factor. This is not a given, as the incidence of such anatomy seen here is much higher than the incidence of the complication generally reported. There should also be examination into whether CCTA could be used in place of standard coronary angiography to evaluate not only for artery anatomy, but also for disease. This would help improve the cost-benefit analysis.

At the end of the day, it remains to be seen what to do with this information. There is the implication that this complication may be exacerbated by a minimally invasive approach. Major alterations in technique as described here are suspect. Perhaps simply being aware of the increased risk would be beneficial. Ultimately, it comes down to attention to suture placement. Most of us are careful drivers; we are even more careful in the rain.

\section{References}

1. Cohn LH. Management of complications related to mitral valve surgery. In Waldhausen JA, Orringer MB, eds. Complications in Cardiothoracic Surgery. St Louis: Mosby-Year Book; 1991:248-50. 
2. Caruso V, Shah U, Sabry H, Gedela S, Birdi I. Mitral valve annulus and circumflex artery: in vivo study of anatomical zones. J Thorac Cardiovasc Surg Tech. 2020;4: 222-9.

3. Li J, Zhao Y, Zhou T, Wany Y, Zhu K, Zhai J, et al. Mitral valve repair for degenerative mitral regurgitation in patients with left ventricular systolic dysfunction: early and mid-term outcomes. J Cardiothorac Surg. 2020;15:284.
4. Hiltrop N, Bennett J, Desmet W. Circumflex coronary artery injury after mitra valve surgery: a report of four cases and comprehensive review of the literature. Catheter Cardiovasc Interv. 2017;89:78-92.

5. Rahmanian PB, Wahlers T. Commentary: circumflex artery injury during mitral valve repair: catching a colibri? Semin Thorac Cardiovasc Surg. 2020;32: 490-1. 